\title{
Assessment of the intrinsic vulnerability of agricultural land to water and nitrogen losses: case studies in Italy and Greece
}

\author{
V. G. ASCHONITIS 1 , M. MASTROCICCO ${ }^{2}$, N. COLOMBANI ${ }^{3}$, E. SALEMI ${ }^{2}$ \& \\ G. CASTALDELLI \\ 1 University of Ferrara, Department of Life Sciences and Biotechnology, Ferrara, Italy \\ 2 University of Ferrara, Department of Physics and Earth Sciences, Ferrara, Italy \\ 3 University "Sapienza" of Rome, Department of Earth Sciences, Rome, Italy \\ nicolo.colombani@uniroma1.it
}

\begin{abstract}
LOS indices (abbr. of Losses) can be used for the assessment of the intrinsic vulnerability of agricultural land to water and nitrogen losses through percolation and runoff. The indices were applied on the lowland region of Ferrara Province (FP) in Italy and the upland region of Sarigkiol Basin (SB) in Greece. The most vulnerable zones in FP were the coastal areas consisting of high permeability sandy dunes and the areas close to riverbanks and palaeochannels, and in SB were the areas characterized by high slopes and high permeability soils at high altitude and areas belonging to the upper part of the alluvial plain close to the boundaries between agricultural land and mountainous regions. The application of LOS indices highlighted the specific features of both lowland and upland regions that contribute to water and nitrogen losses and showed their ability for use as tools in designing environmental management plans.
\end{abstract}

Key words LOS indices; percolation; runoff; intrinsic vulnerability; nitrate

\section{INTRODUCTION}

Nitrate leaching from agricultural land is a worldwide concern, and especially in Europe where a large part of the farmed areas has been affected by nitrate pollution for decades (Howden et al. 2011). Alluvial plains are usually the regions most impacted by nitrate pollution, particularly nitrate groundwater contamination (Cinnirella et al. 2005, Mastrocicco et al. 2011a). The most widely used method for determining water and agrochemical losses from agricultural land is use of process-based mathematical models that describe the water movement, transport and transformations of dissolved species through the soil profile, such as GLEAMS (Knisel and Davis 2000) and HYDRUS (Šimunek et al. 2008). However, simpler models such as classification indices (vulnerability or risk indices) use fewer and more accessible data such as climatic data, topography and general soil physical properties (Gogu and Dassargue 2000). Some popular indices for describing the intrinsic vulnerability of the groundwater to pollution are the DRASTIC index (Aller et al. 1985), SINTACS index (Civita and De Maio 1997), RISKE index (Petelte-Giraude et al. 2000), COP (Zwahlen 2003) and MERLIN (Aveline et al., 2010). The basic problem of these indices is the use of weights and ratings based on subjective criteria; they can be used only in regions where an aquifer system exists and they do not take or partly take into account the different climatic conditions that tend to change nitrogen cycle processes. These facts lead to limitations in their use, leading also to results that are not comparable between regions with different climatic conditions. Due to these limitations, a new approach to describing water and nitrogen losses from agricultural land was followed for the development of LOS indices (Aschonitis et al. 2012); it considers climate data, nitrogen cycle processes and gives special attention to the topsoil (unsaturated zone), which constitutes the door to groundwater pollution. LOS indices have the advantage that they are already calibrated via regression analysis using the results of the GLEAMS model (Knisel and Davis 2000) for the reference crop under various combinations of climate, soil and topographic conditions.

The aim of this study is to present the first application of the LOS indices methodology for the assessment of the intrinsic vulnerability of agricultural land to water and nitrogen losses, in a manner to compare results among different regions. To test the performance of this approach, two heavily impacted agricultural regions with different climate, soil types, land uses and groundwater attributes were selected: the deltaic lowland area of Ferrara Province (FP) in Northern Italy and the upland area of Sarigkiol basin (SB) in Greece. 


\section{MATERIALS AND METHODS}

The LOS indices (Aschonitis et al. 2012) were developed to assess the intrinsic vulnerability of agricultural land to water (LOSW) and nitrogen (LOSN) losses through percolation and runoff based on the simulation results of the GLEAMS V3.0 model (Knisel and Davis 2000). Simulations were performed using reference field-crop characteristics, which concern the top $30 \mathrm{~cm}$ of a uniform reference square area of 1 ha with a homogeneous soil profile, cropped with perennial grass (with an extensive, uniform surface of dense actively growing coverage). The simulation scenarios consisted of various combinations of saturated hydraulic conductivity $K_{s}$, soil organic matter content $O M \%$ (excluding organic soils with carbon:nitrogen ratios $>30$ and with high immobilization rates), surface slope $S \%$, different climatic conditions (temperature $T$, precipitation $P C P$, potential evapotranspiration $P E$ ) and irrigation $I R$ (non-irrigated and irrigated cases). Irrigation was adjusted to keep the soil moisture between $20 \%$ and $100 \%$ of the plant available water content in the soil profile. Fertilization type and rate was constant in all simulations. The parameters of $K_{s}, S \%, P C P, P E$ and $I R$ from the simulation scenarios were used as independent variables in multiple regression analysis to derive the following indices based on the GLEAMS results: the $L O S W-P$ which describes the annual water losses through percolation ( $\left.\mathrm{mm}_{\text {year }}{ }^{-1}\right)$, the $L O S W-R$ which describes the annual water losses through runoff ( $\left.\mathrm{mm}^{-1} \mathrm{ar}^{-1}\right)$ and the $L O S W-P R$ as the sum of water losses obtained from the previous two indices $\left(\mathrm{mm} \mathrm{year}^{-1}\right)$. Apart from the water losses, the LOSW indices can provide an indication of the fate of conservative pollutants. For the case of nitrogen, the same procedure was followed by adding another two independent variables, $O M \%$ and $T$, in order to derive the following indices: the $L O S N-P N$ which describes the annual nitrogen losses through percolation $\left(\mathrm{kg} \mathrm{N} \mathrm{ha}^{-1}\right.$ year $\left.^{-1}\right)$, the $L O S N-R N$ which describes the annual nitrogen losses through runoff $\left(\mathrm{kg} \mathrm{N} \mathrm{ha}^{-1}\right.$ year $\left.^{-1}\right)$ and the LOSN-PRN as the sum of nitrogen losses obtained from the previous two indices $\left(\mathrm{kg} \mathrm{N} \mathrm{ha}^{-1}\right.$ year $\left.^{-1}\right)$. The estimated water and nitrogen losses from the aforementioned indices were used to develop additional indices that provide the mean relative concentration of nitrogen in the percolated water $C P W\left(\mathrm{mg} \mathrm{N} \mathrm{L}^{-1}\right)$ and the respective relative concentration of nitrogen in the runoff water $C R W\left(\mathrm{mg} \mathrm{N} \mathrm{L}^{-1}\right)$. The depth of the groundwater table and the $K_{s}$ values were used to estimate the relative transit time $T T$ (days) of percolated water to reach groundwater. The formulas defining the aforementioned indices, together with an explanation of their derivation, can be found in Aschonitis et al. (2012) while additional LOS indices describing the intrinsic rates of nitrogen transformations are provided in Aschonitis et al. (2013).

LOS indices were applied in two case studies: the FP (Italy), covering an area of $2623.4 \mathrm{~km}^{2}$, and the SB (Greece), covering an area of $469.2 \mathrm{~km}^{2}$ (Fig. 1). The minimum, maximum and mean altitude for the FP are $-11.0,38.0$ and $0.5 \mathrm{~m}$ above sea level (a.s.1.), and for the SB are 640.0, 1796.1 and $952.4 \mathrm{~m}$ a.s.1., respectively. Slope models for each region were obtained from national digital elevation models (DEMs).

The FP is part of the Upper Adriatic climatic sector and can be divided into two zones: a "coastal zone" stretching from the sea to $30 \mathrm{~km}$ inland and a "peri-coastal zone" located on the west side of the province. The whole area has a temperate climate with sub-continental characteristics, cold winters and warm summers. The SB is characterized by a semi-arid, Mediterranean climate with the most rainfall in autumn and spring, while summers are usually dry. Precipitation $P C P$ and temperature $T$ maps were developed from surface interpolation of data obtained at local meteorological stations. Potential evapotranspiration, $P E$, was determined using the Thornthwaite and Mather method (Black 2007) in both case studies. Irrigation, $I R$, was estimated as the sum of monthly deficits of $P C P$ to cover PE (Aschonitis et al. 2013).

Land use for the study areas was identified using CORINE Land Cover 2000, while crop distribution was obtained from the reports of the regional administrative units. For FP, surface integration of hydraulic conductivity, $K_{s}$, was carried out using values that were determined for the 12 soil texture classes according to the USDA soil taxonomy based on the Green-Ampt equation approach (Liu et al. 2008). Surface integration of organic matter was based on a wide number of field measurements that cover the entire region (SGSS, http://www.regione.emilia-romagna.it/ 
$\mathrm{wcm} /$ geologia/index.htm). For SB, surface integration of $K_{s}$ was carried out using the average value of two pedotransfer functions (PTFs): the parametric sand dependent PTF of Ferrer-Julia $e t$ al. (2004) and the clay dependent PTF of Dane and Puckett (1994); organic matter was determined using Dexter's PTF (2004).

The FP surface waters consist of both natural and artificial bodies. The latter, used for drainage purposes, have a total length of more than $3500 \mathrm{~km}$. In the FP, the unconfined aquifer texture is sand and silty-sand, with higher spatial heterogeneity due to the presence of palaeochannels and alluvial fans interconnected with alluvial fan and marsh lagoon environments (Amorosi et al. 2003). The unconfined aquifer thickness usually ranges between 2 and $7 \mathrm{~m}$, but in some cases may exceed $45 \mathrm{~m}$ (Mastrocicco et al. 2011b). The water table depth ranges between 0.5 and $5.5 \mathrm{~m}$ below ground level (b.g.1.). Significant surface water bodies do not exist in the SB except for the Soulou torrent (or Eordaios), which was artificially excavated for use as the main drainage ditch to support secondary ditches. The alluvial deposits in the centre of the SB host an unconfined aquifer superimposed on successive confined or semi-confined aquifers, covering an area of approx. $60 \mathrm{~km}^{2}$. The depth of the water table in the alluvial aquifer ranges from 7 to $75 \mathrm{~m}$ b.g.l., i.e. 585-730 $\mathrm{m}$ a.s.l. For both regions, maps of groundwater elevation were developed using surface interpolation of piezometric data.

The thematic base maps for both the FP and the SB were developed using ArcGIS 9.3 ESRI software and their mean pixel values are given in Fig. 1.

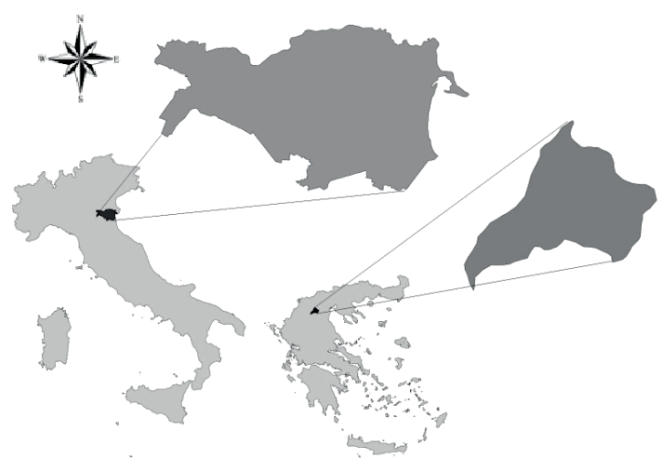

\begin{tabular}{cccc}
\hline Base & \multirow{2}{*}{ Unit } & FP & SB \\
\cline { 3 - 4 } maps & & Mean \pm S.D. & Mean \pm S.D. \\
\hline$T$ & ${ }^{\circ} \mathrm{C}$ & $13.1 \pm 0.3$ & $12.7 \pm 1.1$ \\
$P C P$ & mm year $^{-1}$ & $650 \pm 44$ & $575 \pm 45.3$ \\
$P E$ & mm year $^{-1}$ & $780.8 \pm 9.7$ & $750.7 \pm 47.9$ \\
$K_{s}$ & mm day $^{-1}$ & $489.3 \pm 1231.8$ & $530.2 \pm 433.6$ \\
$O M$ & $\%$ & $1.3 \pm 0.3$ & $2.5 \pm 0.5$ \\
$\mathrm{~S}$ & $\%$ & $0.8 \pm 0.7$ & $3.9 \pm 5.5$ \\
$I R$ & mm year $^{-1}$ & 253.9 & 342.4 \\
\hline
\end{tabular}

Fig. 1 Location of Ferrara province in Italy (FP) and of Sarigkiol basin (SB) in Greece, and the mean pixel values for each base map.

\section{RESULTS AND DISCUSSION}

\section{Case study of Ferrara Province (FP) - Italy}

The application of $L O S W$ indices in FP (Fig. 2(a)-(c)) showed that the water losses through percolation (LOSW-P) (Fig. 2(a)) are greater in the coastal region, where the soil texture is dominated by the sand of the dunes having high $K_{s}$ values. The water losses through surface runoff $(L O S W-R)$ (Fig. 2(b)), are higher in the western and south-central regions of FP due to a combination of higher $S$, lower $K_{s}$ values and higher $P C P$. The resulting total water losses (LOSW-PR) (Fig. 2(c)) show that the most vulnerable zones in FP are the south-central part, close to the Reno riverbank and, secondly, the coastal dunes.

According to the LOSN indices (Fig. 2(d)-(f)), the nitrogen losses through percolation (LOSN$P N)$ (Fig. 2(d)), are higher in the coastal dunes and follow the $L O S W-P$ pattern, but medium values are also observed along the riverbanks consisting of palaeochannels and the alluvial fans of the Po and Reno rivers which are characterized by high $K_{s}$ values. The nitrogen losses through surface runoff (LOSN-RN) (Fig. 2(e)) show an analogous distribution to $L O S W-R$ (Fig. 2(b)). The resulting total nitrogen losses (LOSN-PRN) (Fig. 2(f)) show that the most vulnerable zone is in the coastal region. Peaty soils were excluded from the $L O S N$ indices analysis because the soil organic matter content is beyond the range considered in the calibration of the LOSN indices (Aschonitis et al. 2012). Finally, higher relative nitrogen concentrations in the runoff water $(C R W)$ are observed in 


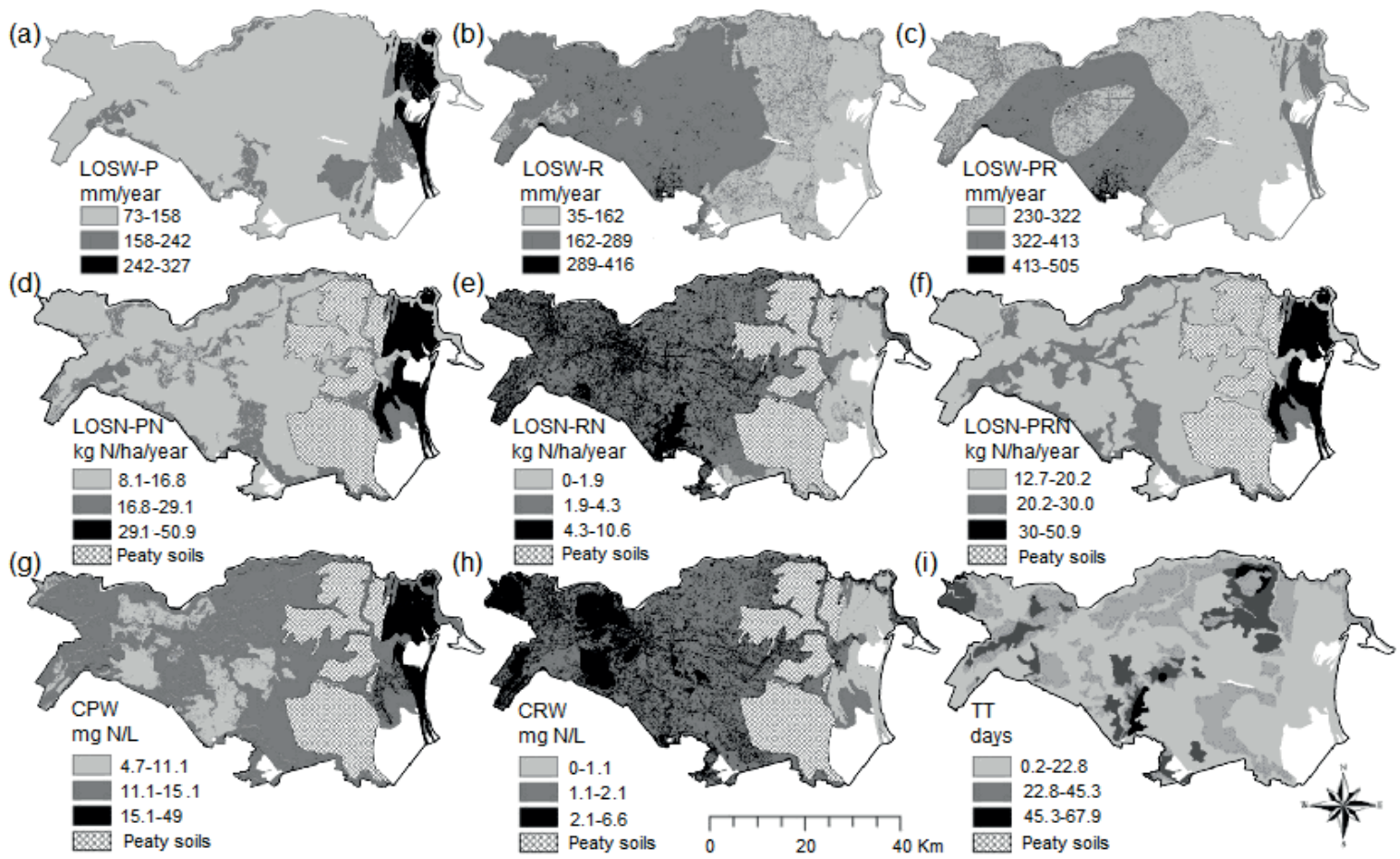

Fig. 2 (a) $L O S W-P\left(\mathrm{~mm}\right.$ year $\left.{ }^{-1}\right)$, (b) $L O S W-R\left(\mathrm{~mm} \mathrm{year}^{-1}\right)$, (c) $L O S W-P R\left(\mathrm{~mm}^{-1} \mathrm{rr}^{-1}\right)$, (d) $L O S N-P N(\mathrm{~kg}$ $\mathrm{N} \mathrm{ha}{ }^{-1}$ year $\left.^{-1}\right)$, (e) $L O S N-R N\left(\mathrm{~kg} \mathrm{~N} \mathrm{ha}^{-1}\right.$ year $\left.{ }^{-1}\right)$, (f) $L O S N-P R N\left(\mathrm{~kg} \mathrm{~N} \mathrm{ha}^{-1}\right.$ year $\left.{ }^{-1}\right),(\mathrm{g}) C P W\left(\mathrm{mg} \mathrm{L}^{-1}\right),(\mathrm{h})$ $C R W\left(\mathrm{mg} \mathrm{L}^{-1}\right)$ and (i) $T T$ (days) for the Ferrara Province (FP) region in Italy.

the west region (Fig. 2(h)). Higher relative nitrogen concentrations in the percolated water $(C P W)$ are observed in the coastal region (Fig. 2(g)), which also presents the lower values of the relative transit time $T T$ (Fig. 2(i)). Consequently the coastal region has a higher pollution potential of underlying groundwater.

\section{Case study of Sarigkiol Basin (SB) - Greece}

The application of LOSW indices in SB (Fig. 3(a)-(c)) showed that water losses through percolation (LOSW-P) (Fig. 3(a)) are lower in the centre of the basin and increase towards the fringes due to the transition from fine textured soils with low $K_{s}$ to coarser soils with higher $K_{s}$, especially in the northeastern region. The water losses through surface runoff $(L O S W-R)$ are higher in the eastern region due to higher slopes while medium values are observed in the centre of the region due to low $K_{s}$ values (Fig. 3(b)). The total water losses (LOSW-PR) show that the most vulnerable zone of SB is the northeastern region (Fig. 3(c)).

Nitrogen losses through percolation $(L O S N-P N)$ show a distribution analogous to $L O S W-P$ (Fig. 3(d)). Water losses through surface runoff ( $L O S N-R N$ ) (Fig. 3(e)) indicate higher values in the eastern region due to higher slopes. The total nitrogen losses (LOSN-PRN) (Fig. 3(f)) indicate that the most vulnerable zone is the northeastern region and the areas close to the boundaries of the aquifer. The highest nitrogen concentrations in percolated water $(C P W)$ (Fig. 3(g)) are observed in the regions close to the edge of the aquifer, while the highest nitrogen concentrations in the runoff water $(C R W)$ (Fig. 3(h)) occur in the northeastern region of SB. The relative transit time map (Fig. 3(i)) is restricted to only the region defined by the aquifer boundaries and values gradually increase from the lowland central-west part to the eastern upland region.

\section{Comparison of the two case studies}

The mean values of the LOS indices for FP and SB were used to compare the resulting intrinsic vulnerability of the two regions (Table 1). The mean $L O S W-P$ values were similar in both regions 


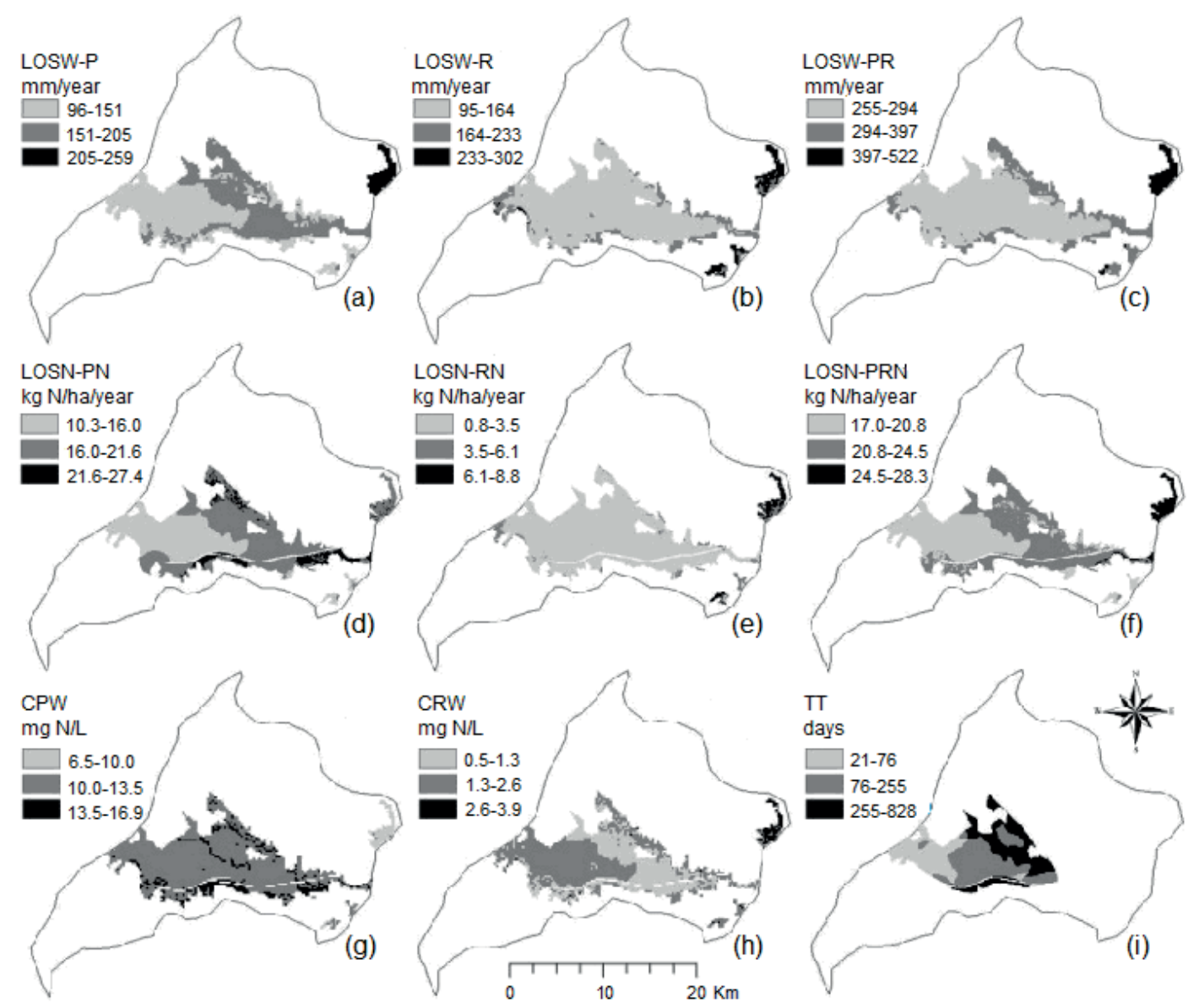

Fig. 3 (a) $L O S W-P\left(\mathrm{~mm} \mathrm{year}^{-1}\right)$, (b) $L O S W-R\left(\mathrm{~mm} \mathrm{year}^{-1}\right)$, (c) $L O S W-P R\left(\mathrm{~mm} \mathrm{year}^{-1}\right)$, (d) $L O S N-P N(\mathrm{~kg}$ $\mathrm{N}$ ha $^{-1}$ year $\left.{ }^{-1}\right)$, (e) $L O S N-R N\left(\mathrm{~kg} \mathrm{~N} \mathrm{ha}^{-1}\right.$ year $\left.^{-1}\right)$, (f) $L O S N-P R N\left(\mathrm{~kg} \mathrm{~N}^{-1}\right.$ year $\left.{ }^{-1}\right),(\mathrm{g}) C P W\left(\mathrm{mg} \mathrm{L}^{-1}\right),(\mathrm{h})$ $C R W\left(\mathrm{mg} \mathrm{L}^{-1}\right)$ and (i) $T T$ (days) for the Sarigkiol Basin (SB) region in Greece.

while $L O S W-R$ values were approximately $18 \%$ higher in FP than in SB, leading to higher total water losses $(L O S W-P R)$, a difference which can be mainly ascribed to the higher annual precipitation and the lower potential evapotranspiration in FP. The mean values of $L O S N-P N$, $L O S N-R N, L O S N-P R N, C P W$ and $C R W$ were similar in both regions. Taking into account the $T T$ values, FP can be considered more vulnerable than SB due to the higher water table and the shorter transit time necessary to reach the groundwater for both water and nitrogen species.

Table 1 Minimum, maximum and mean pixel values for each LOS index.

\begin{tabular}{|c|c|c|c|c|c|c|c|}
\hline \multirow[t]{2}{*}{ LOS indices } & \multirow[t]{2}{*}{ Unit } & \multicolumn{3}{|l|}{ FP: } & \multicolumn{3}{|l|}{ SB: } \\
\hline & & Min & $\operatorname{Max}$ & Mean \pm S.D. & Min & Max & Mean \pm S.D. \\
\hline LOSW-P & $\mathrm{mm}$ year $^{-1}$ & 73 & 327 & $144 \pm 42$ & 96 & 259 & $146.5 \pm 23.3$ \\
\hline$L O S W-R$ & mm year ${ }^{-1}$ & 35 & 416 & $170 \pm 51$ & 95 & 302 & $143.8 \pm 41.2$ \\
\hline$L O S W-P R$ & $\mathrm{~mm}$ year $^{-1}$ & 230 & 505 & $314 \pm 37.2$ & 255 & 522 & $290.4 \pm 51.6$ \\
\hline$L O S N-P N$ & $\mathrm{~N} \mathrm{~kg} \mathrm{ha}^{-1}$ year $^{-1}$ & 8.1 & 50.9 & $17.2 \pm 8.0$ & 10.3 & 27.4 & $18.1 \pm 2.6$ \\
\hline$L O S N-R N$ & $\mathrm{~N} \mathrm{~kg} \mathrm{ha}^{-1}$ year $^{-1}$ & 0 & 10.6 & $3.2 \pm 1.4$ & 0.8 & 8.8 & $2.2 \pm 1.3$ \\
\hline$L O S N-P R N$ & $\mathrm{~N} \mathrm{~kg} \mathrm{ha}^{-1}$ year $^{-1}$ & 12.7 & 50.9 & $20.4 \pm 7.0$ & 17 & 28.3 & $20.3 \pm 2.5$ \\
\hline$C P W$ & $\mathrm{~N} \mathrm{mg} \mathrm{L}^{-1}$ & 4.7 & 49 & $12.1 \pm 1.6$ & 6.5 & 16.9 & $12.6 \pm 1.3$ \\
\hline$C R W$ & $\mathrm{~N} \mathrm{mg} \mathrm{L}{ }^{-1}$ & 0 & 6.6 & $1.8 \pm 0.5$ & 0.5 & 3.9 & $1.5 \pm 0.4$ \\
\hline$T T$ & days & 0.2 & 67.9 & $21.2 \pm 18.5$ & 21 & 828 & $185 \pm 147$ \\
\hline
\end{tabular}




\section{CONCLUSIONS}

The application of LOS indices highlighted the specific features of both lowland and upland regions which contribute to water and nitrogen losses. The indices can be used as a tool to design irrigation and drainage schemes in places with high water and nitrogen losses due to percolation, and measures (e.g. land levelling, tied soil ridges, vegetated contour strips, etc.) to reduce runoff, always giving priority to the more vulnerable zones. The indices can be employed easily in largescale applications with few data using Geographical Information Systems (GIS), and they can efficiently support Decision Support Systems and cost-benefit analyses to improve the environmental and economic sustainability of agricultural systems.

\section{REFERENCES}

Aller, L., et al. (1985) Drastic: a standardized system for evaluating groundwater pollution potential using hydrogeologic settings. EPA/600/2-85/018, U.S. Environmental Protection Agency, USA.

Amorosi, A., et al. (2003) Facies architecture and latest Pleistocene-Holocene depositional history of the Po Delta (Comacchio area), Italy. J. Geology 111, 39-56.

Aschonitis, V., et al. (2012) Assessment of the intrinsic vulnerability of agricultural land to water and nitrogen losses, via deterministic approach and regression analysis. Water Air Soil Poll. 223(4), 1605-1614.

Aschonitis, V., et al. (2013) Formulation of indices to describe intrinsic nitrogen transformation rates for the implementation of best management practices in agricultural lands. Water Air Soil Poll. 224, 1489.

Aveline, A., et al. (2009) Evaluating an environmental indicator: Case study of MERLIN, a method for assessing the risk of nitrate leaching. Agr. Syst. 100, 22-30.

Black, P. E. (2007) Revisiting the Thornthwaite and Mather Water Balance, 1. J. Am. Water Resour. As. 43(6), 1604-1605.

Cinnirella, S., Buttafuoco, G. and Pirronea, N. (2005) Stochastic analysis to assess the spatial distribution of groundwater NO3concentrations in the Po catchment (Italy). Environ. Pollut. 133, 569-580.

Civita, M. and De Maio, M. (1997) SINTACS - Un sistema parametrico per la valutazione e la cartografia della vulnerabilità degli acquiferi all'nquinamento. Quaderni di tecniche di protezione ambientale n. 60. Pitagora Editrice, Bologna, Italy.

Dane, J. H. and Puckett, W. (1994) Field soil hydraulic properties based on physical and mineralogical information. In: Proceedings of the International Workshop on Indirect Methods for Estimating the Hydraulic Properties of Unsaturated Soils (eds. by van Genuchten M.Th. et al.), University of California, Riverside, USA.

Dexter, A. R. (2004) Soil physical quality: Part I. Theory, effects of soil texture, density, and organic matter, and effects on root growth. Geoderma 120, 201-214.

Ferrer-Julia, M., et al. (2004) Constructing a saturated hydraulic conductivity map of Spain using pedotransfer functions and spatial prediction. Geoderma 123, 257-277.

Gogu, R. C. and Dassargue, A. (2000) Current trends and future challenges in groundwater vulnerability assessment using overlay and index methods. Environ. Geol. 39(6), 549-559.

Howden, N .J. K., et al. (2011) Nitrate pollution in intensively farmed regions: What are the prospects for sustaining highquality groundwater? Water Resour. Res. 47, W00L02, doi:10.1029/2011WR010843.

Knisel, W. G. and Davis, F. M. (2000) GLEAMS, Groundwater loading effects from agricultural management systems V3.0. U.S.D.A., Publ. No. SEWRL-WGK/FMD-050199, Tifton, Georgia.

Liu, J., Zhang, J. and Feng, J. (2008) Green-Ampt model for layered soils with nonuniform initial water content under unsteady infiltration. Soil Sci. Soc. Am. J. 72, 1041-1047.

Mastrocicco, M., et al. (2011a) Monitoring and modeling nitrate persistence in a shallow aquifer. Water Air Soil Poll. 217(1-4), 83-93.

Mastrocicco, M., et al. (2011b) Large tank experiment on nitrate fate and transport: the role of permeability distribution. Environ. Earth Sci. 63(5), 903-914.

Petelte-Giraude, E., Dorfliger, N. and Crochet, P. (2000) RISKE: Methode d'evaluation multicritere de la cartographie de la vulnerabilite des aquiferes karstiques. Applications aux systemes des Fontanilles et Cent-Fonts (Herault, France). Hydrogeologie 4, 71-88.

Šimunek, J., et al. (2008) The HYDRUS-1D software package for simulating the movement of water, heat, and multiple solutes in variably saturated media, Version 4.0, HYDRUS Software Series 3. Department of Environmental Sciences, University of California Riverside, Riverside, California, USA.

Zwahlen, F. (2003) Vulnerability and risk mapping for the protection of carbonate (karst) aquifers. European Commission Cost Action 620 report. 